\title{
INFLUENCE OF DEFORMED SURFACE LAYER WHEN MACHINING WROUGHT ALLOY 718 IN AN ANNEALED AND IN A PRE-STRAINED CONDITION
}

\author{
Stefan Cedergren $^{1}$, Joakim Johansson ${ }^{1}$, Göran Sjöberg ${ }^{1}$ \\ ${ }^{1}$ Chalmers University of Technology; Rännvägen 2A, 41296 Gothenburg, Sweden \\ Keywords: Machining, Superalloy 718, Aerospace
}

\begin{abstract}
Superalloys are difficult to cut, mainly due to their preserved strength at elevated temperatures and their exceptional work hardening, where the latter results in a deformed layer on the machined surface. The thickness and degree of deformation of this layer depends on several parameters, such as cutting speed, uncut chip thickness, tool material and edge geometry. This layer enters the cutting zone of subsequent revolutions in turning or in milling. Under certain circumstances, as when the uncut chip thickness is small, all deformation at subsequent machining takes place within the deformed layer. The same phenomenon may occur at the outer edge of the cutting zone where the unrestricted material flow leads to burr formation. The deformed layer at the outer edge is suggested as the cause for notch wear often found when machining Superalloys.
\end{abstract}

In this paper the effect of deformed layer on machining is examined through controlled experiments on the material in to different states of strain; in the annealed state without any remaining strain and with a substantial amount introduced by tensile straining. The results showed that cutting forces were reduced when pre-straining the material. Tool wear was similar in both materials, with large scatter due to built-up edge formation.

\section{Introduction}

Superalloys are widely used in the hotter sections of gas turbines, due to their excellent high temperature properties [1]. Their much appreciated in-service ability to retain the mechanical properties at elevated temperature is also what causes their poor machinability properties during manufacturing [2]. The strong strain hardening tendency results in a significant hardened layer on machined surfaces, the extent of which, depends on the cutting parameters such as speed, feed rate, tool material and geometry $[3,4]$. The hardened surface, which enters into the cutting zone of the subsequent cuts, is one of the most interesting causes, among those suggested, for notch wear formation $[2,5,6]$. This leads to the conclusion that the influence of prior plastic deformation on the machining process seems to be of interest.

A deliberate study of the effects of deformed layers in the workpiece material can be made possible by using two different initial strain conditions; the as annealed condition, where any previous strain is annihilated, and another condition in which a pre-deformation strain is introduced. The strain deformation in the pre-deformed material condition can e.g. be accomplished by sheet material test pieces utilizing a tensile testing machine. 
With the material in these two different strain conditions a systematic comparison is then possible of the effect of the previous state of strain in the material. This can be accomplished by peripheral down-milling of test pieces while, at the same time, the torque required during machining and the tool wear may be studied.

\section{Experimental}

Work material

Cold rolled and annealed Alloy 718 sheet material with a thickness of $1.65 \mathrm{~mm}$ and a grain size of ASTM 9 was used during the experiments. Chemical composition can be found in Table I.

Table I. Chemical composition of the work material used.

\begin{tabular}{|c|c|c|c|c|c|c|c|c|}
\hline $\mathrm{C}$ & $\mathrm{Mn}$ & $\mathrm{Fe}$ & $\mathrm{S}$ & $\mathrm{Si}$ & $\mathrm{Cu}$ & $\mathrm{Ni}$ & $\mathrm{Cr}$ & $\mathrm{Al}$ \\
\hline 0.03 & 0.08 & 17.57 & 0.0003 & 0.11 & 0.12 & 53.84 & 18.67 & 0.52 \\
\hline $\mathrm{Ti}$ & $\mathrm{Co}$ & $\mathrm{Mo}$ & $\mathrm{Nb}$ & $\mathrm{Ta}$ & $\mathrm{P}$ & $\mathrm{B}$ & $\mathrm{Nb}+\mathrm{Ta}$ & \\
\hline 0.97 & 0.17 & 2.89 & 4.98 & $<0.01$ & 0.01 & 0.002 & 4.98 & \\
\hline
\end{tabular}

All straining was performed parallel to the rolling direction of the sheet. The pre-strained samples experienced an engineering strain of $30 \%$ by which the yield strength increased from 510 to $1120 \mathrm{MPa}$. The true stress and strain evolvement during the elongation of the pre-strained test specimens can be seen in Figure 1. Comparison of the hardness measured in the as received annealed material and in the pre-strained material, as the mean value of five measurements, can be found in Table II. The thickness was reduced from 1.65 to $1.43 \mathrm{~mm}$.

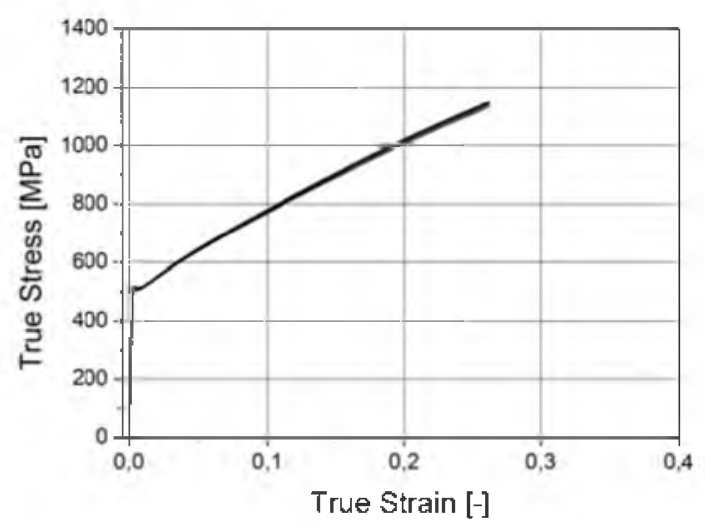

Figure 1. True stress and strain during drawing of pre-strained samples.

Table II. Hardness values of as received and pre-strained material conditions.

\begin{tabular}{|c|c|}
\hline Material condition & $\mathbf{H V}_{\mathbf{1 0}}$ \\
\hline As received (annealed) & 238 \\
\hline Pre-strained & 351 \\
\hline
\end{tabular}




\section{Machining}

All milling experiments were carried out in a AgieCharmilles Mikron HPM 600 HD CNC milling machine. Solid AlTiN coated tungsten carbide four flute end mills, with 30 degree helix angle from SGS were used during both torque and wear measurement experiments. The chosen machining operation was peripheral down-milling, with the end mill fully engaged with the sheet workpiece in axial direction and with a radial depth of cut of $1 \mathrm{~mm}$. Figure 2 shows the setup during tool wear tests with three tool passes between re-clamping of workpiece.

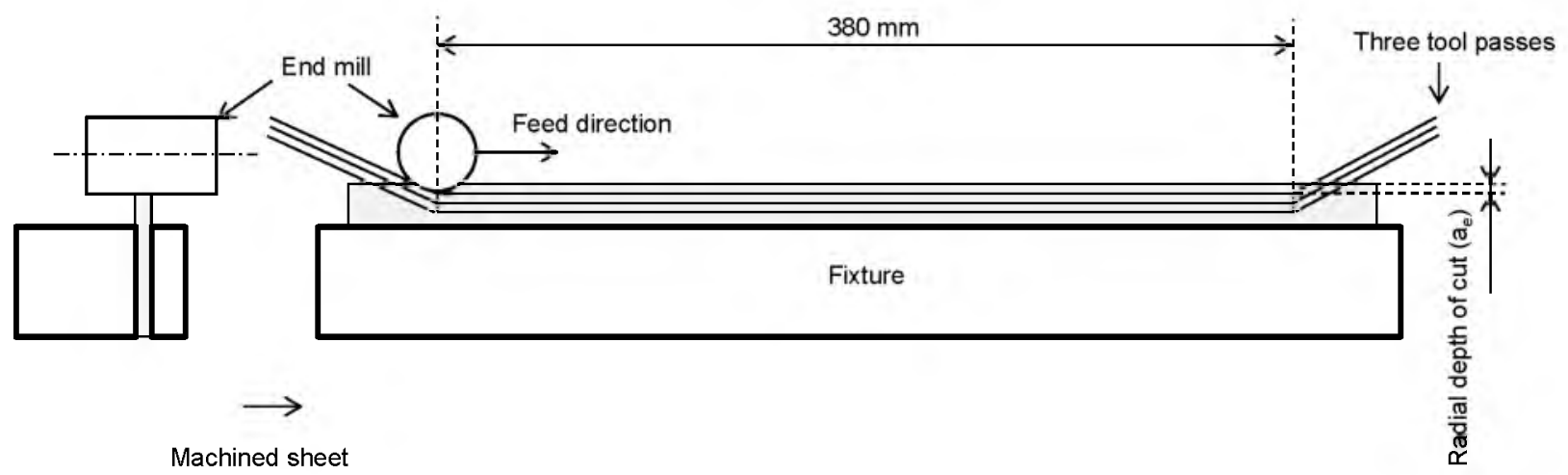

Figure 2. Machining set-up during tool wear tests.

\section{$\underline{\text { Torque measurement }}$}

Torque was measured using a Kistler rotating multicomponent dynamometer Type 9170A connected to a signal conditioner Type $5238 \mathrm{~B}$. All experiments were run under dry conditions. Three different cutting speeds were tested; 30,45 and $60 \mathrm{~m} / \mathrm{min}$ respectively, each at three different feed rates resulting in maximum nominal chip thicknesses of $0.02,0.06$ and $0.10 \mathrm{~mm}$. All experiments were repeated at least two times, with new cutting edges used every time. Torque values were taken as mean values of the maximum torque during twelve consecutive tooth-workpiece engagements.

\section{$\underline{\text { Tool wear }}$}

Flood coolant was applied during tool wear tests; emulsion CareCut S600 from Castrol at 5.5\% concentration. Tool wear was measured every third tool pass, with the aid of a Zeiss Discovery V20 stereo microscope. Cutting data was chosen after the torque had been measured, where feed rate corresponding to maximum chip thickness of $0.06 \mathrm{~mm}$ was chosen due to the fact that it showed some difference in torque values between the two tested material conditions. The highest value of $0.1 \mathrm{~mm}$ in chip thickness was rejected, even though it also showed differences in torque, since severe tool chipping was observed after machining. First tests were run at the highest cutting speed from torque tests, i.e. $60 \mathrm{~m} / \mathrm{min}$, this was later increased to 90 and $120 \mathrm{~m} / \mathrm{min}$ respectively to increase wear rate. All tests were repeated once. 


\section{Results}

$\underline{\text { Torque measurement }}$

The torque measurements showed a slight decrease when machining pre-strained material compared to as received at higher feed rates (see Figure 3-Figure 5).

\section{Cutting speed $30 \mathrm{~m} / \mathrm{min}$}

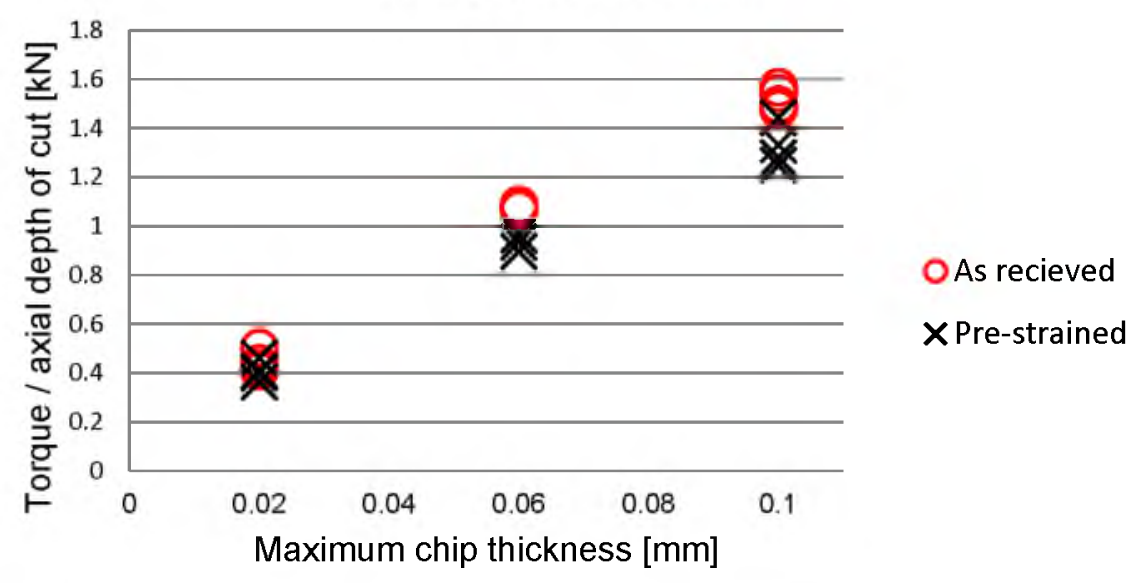

Figure 3 . Torque measurement at $30 \mathrm{~m} / \mathrm{min}$.

\section{Cutting speed $45 \mathrm{~m} / \mathrm{min}$}

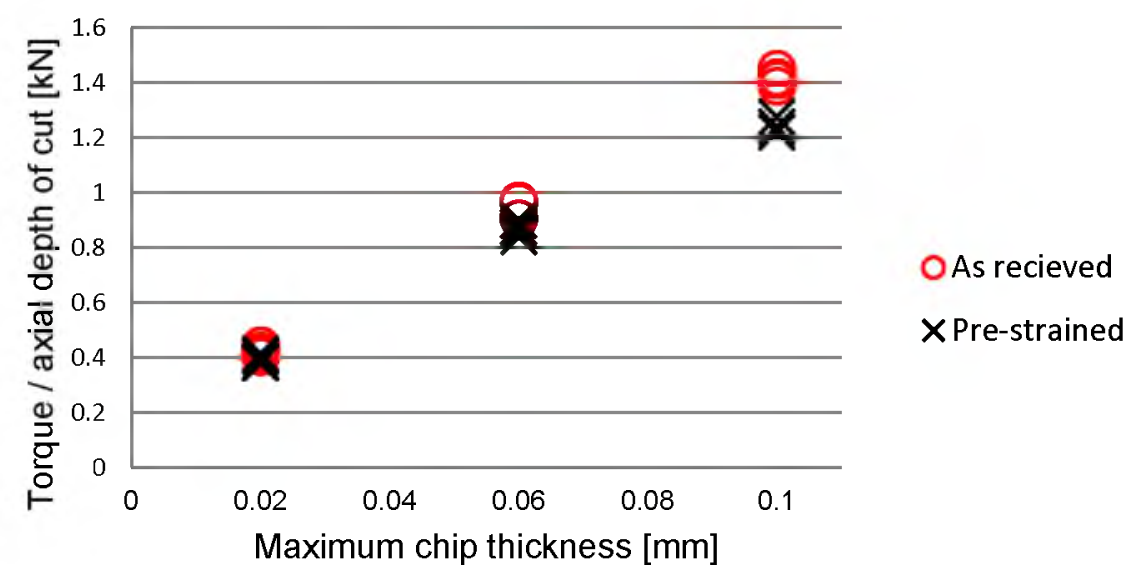

Figure 4 . Torque measurement at $45 \mathrm{~m} / \mathrm{min}$. 


\section{Cutting speed $60 \mathrm{~m} / \mathrm{min}$}

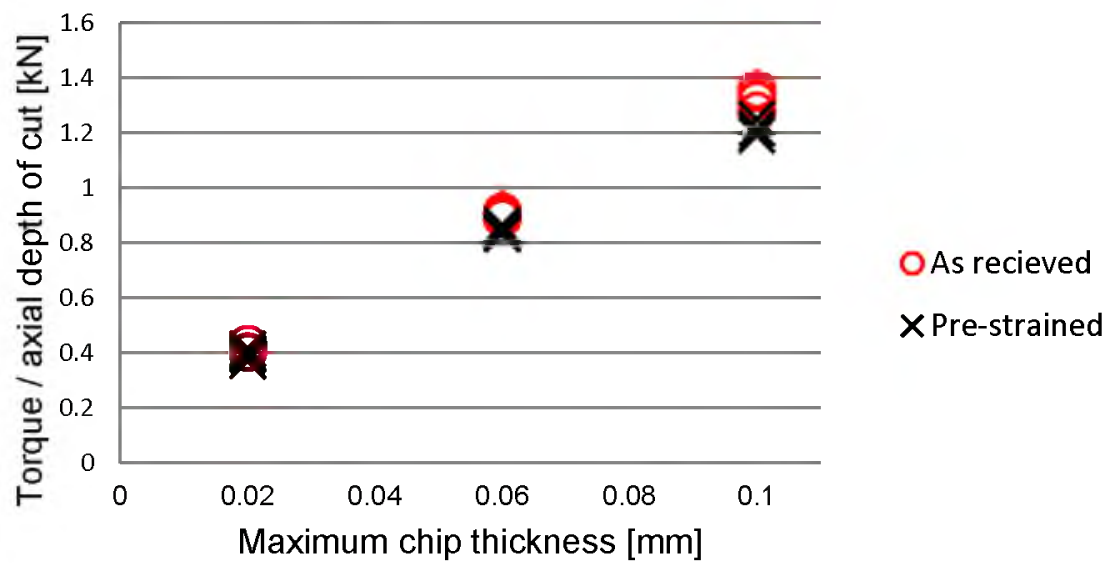

Figure 5. Torque measurement at $60 \mathrm{~m} / \mathrm{min}$.

\section{$\underline{\text { Wear measurement }}$}

The wear measurements show no significant difference between the two materials. Figure 6Figure 8 present the wear of all four flutes in both replicates for every cutting condition. Builtup edges were formed to some degree on most tool edges, explaining the large spread in wear, as well as the tool failures as the adhered material pulls out tool material inconsistently (see Table III)

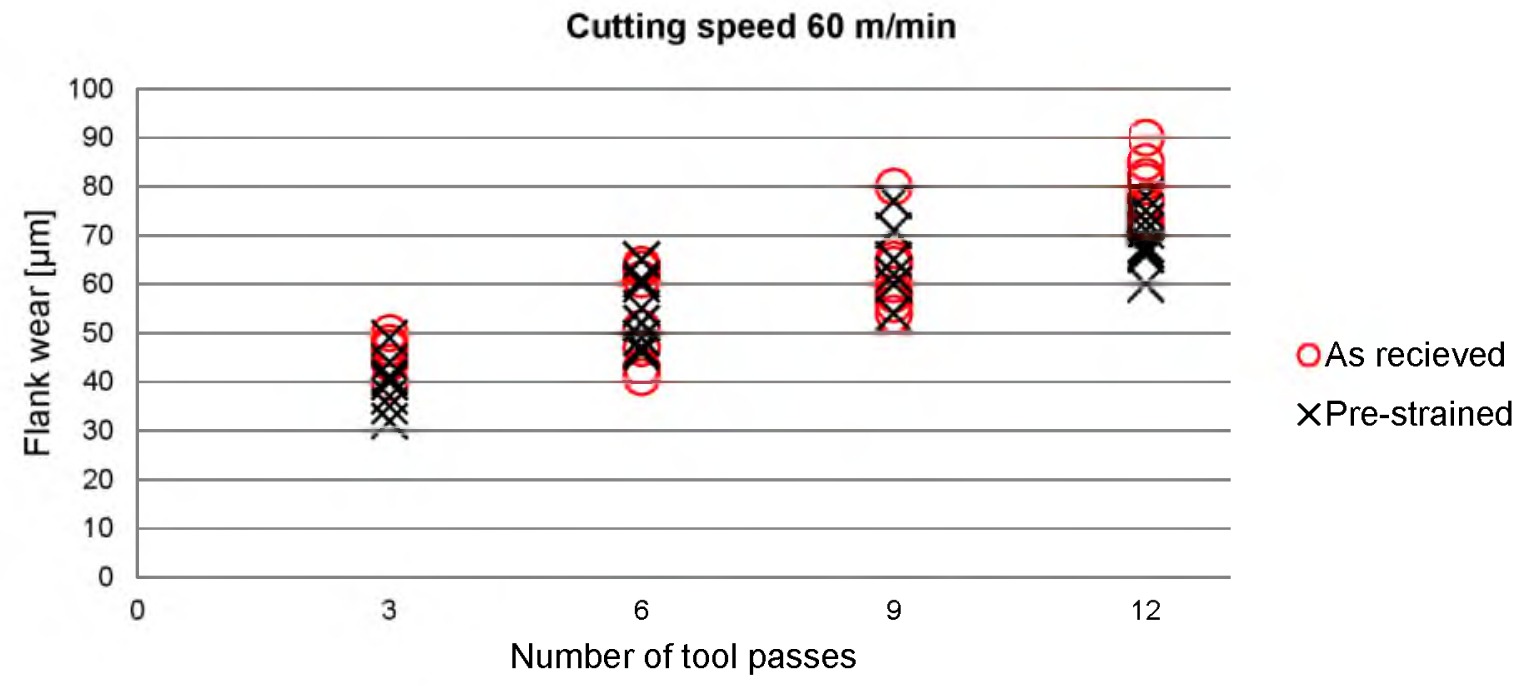

Figure 6. Tool wear at $60 \mathrm{~m} / \mathrm{min}$. 
Cutting speed $90 \mathrm{~m} / \mathrm{min}$

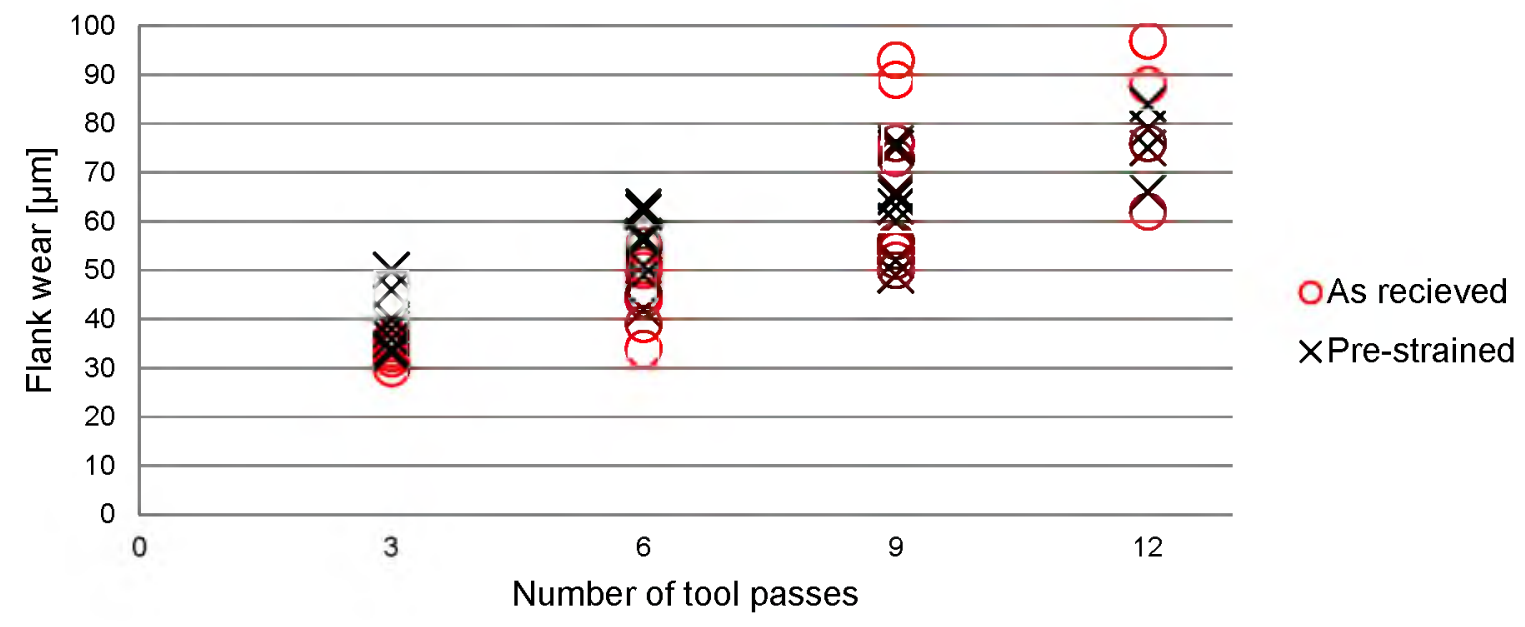

Figure 7. Tool wear at $90 \mathrm{~m} / \mathrm{min}$, some data missing at 12 passes due to tool failure.

Cutting speed $120 \mathrm{~m} / \mathrm{min}$

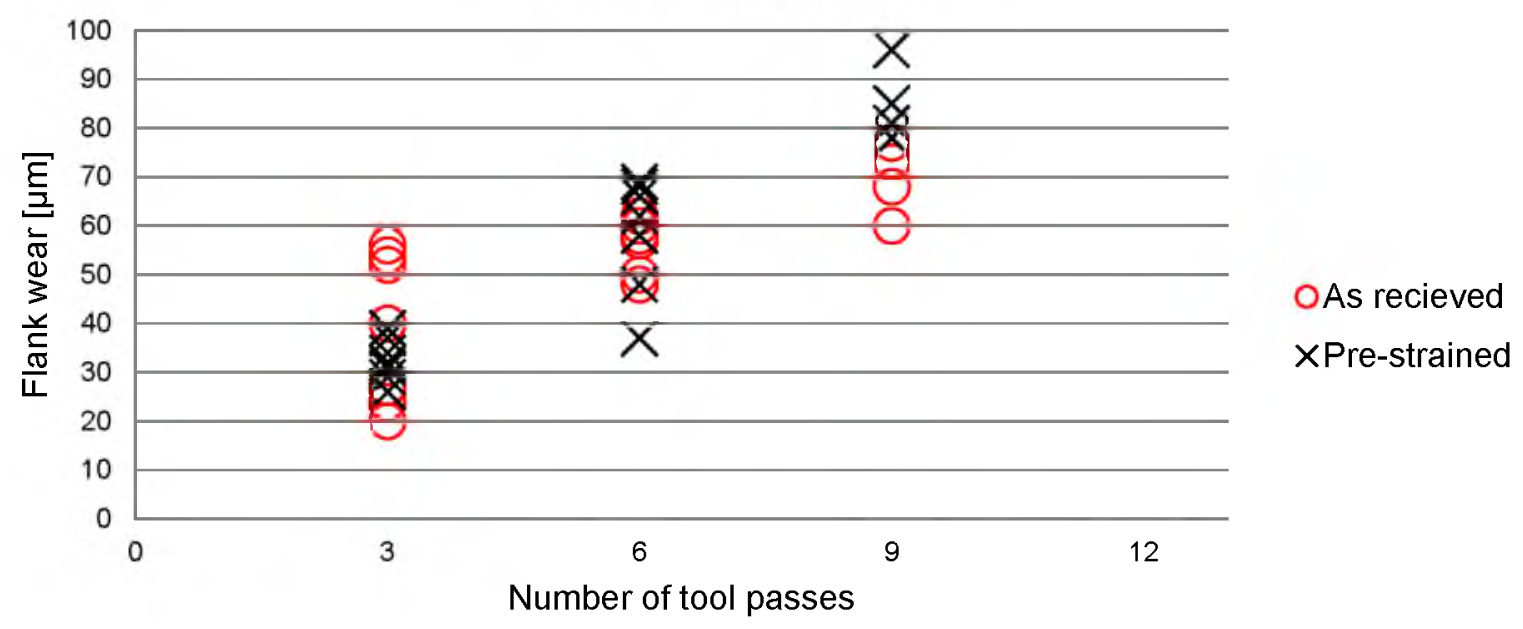

Figure 8 . Tool wear at $120 \mathrm{~m} / \mathrm{min}$, data missing at $9-12$ passes due to tool failure.

Table III. Compilation of tool failures that occurred during tool wear testing.

\begin{tabular}{|l|l|c|}
\hline Cutting speed & Material & Tool failure at [\#passes] \\
\hline 60 & Pre-strained & 12 \\
\hline 90 & As received & 11 \\
\hline 120 & Pre-strained & 9 \\
\hline 120 & Pre-strained & 11 \\
\hline 120 & As received & 9 \\
\hline 120 & As received & 11 \\
\hline
\end{tabular}




\section{Discussion}

While no significant difference in tool wear was found, the large scatter calls for more replicates in order to be able to tell if there are any small differences. Thus, deformed surfaces with strains on the same level as the ones tested in the present study, does not seem to be detrimental to tool wear, even though yield strength was increased by a factor of two in the pre-strained material. However, the amount of tool failures did increase with cutting speed, regardless of workpiece material, it is therefore recommended to stay below $120 \mathrm{~m} / \mathrm{min}$.

The large scatter found in tool wear might have been further aggravated by the relatively compliant workpiece causing unwanted relative movement between tool and machined material, thereby accelerating tool wear through built-up edge formation with subsequent pull-out of tool material. The deflection of the workpiece was not measured, however.

Chip morphology was studied, since superalloys are known to undergo a transition from continuous to shear-localized chip formation when cutting speed is increased [7]. One of the proposed mechanisms for this transition is thermoplastic shear-instability also known as adiabatic shear-localization. This instability is also affected by chip thickness, were an increase in feed favors the transition to shear-localized chips [8]. However, no localization was found even at high speeds and feed rates, with the exception of some serrations observed at one of the sides of the chip, see Figure 9.

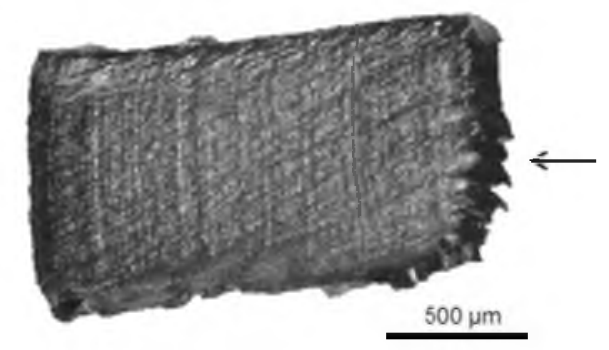

Figure 9. Free surface of chip formed when machining pre-strained material with a cutting speed of $60 \mathrm{~m} / \mathrm{min}$ and a nominal maximum chip thickness of $0.1 \mathrm{~mm}$. Arrow indicates serrations at outer edge.

This has also been observed during turning, where the transition to shear-localized chips started at the outer edge [9]. A possible explanation for this is the stress-state of the chip at the outer edge, which is under plane stress, as opposed to the body of the chip which is formed under plane strain conditions [6]. The reason why only one side is serrated could be explained by the fact that the helix angle of the end mill enhances plane stress on one side and reduces it at the other. This can also be seen when the machined workpieces are investigated. A burr is formed in the as received condition at the same edge as the serrations on chip are found, indicating differences in stress-states, see Figure 10. Interestingly, no burrs where formed on the predeformed workpieces, thus it seems as if the reduced ductility of the workpiece will reduce the side-flow at the outer edges of the chip formation zone. 


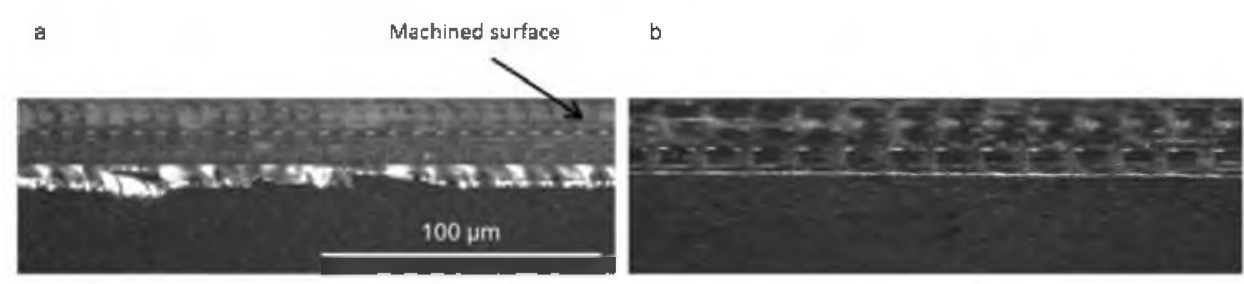

Figure 10. Burr formation in as received material (a) and pre-strained material (b)

Adiabatic shear-localization is initiated when the thermal softening of the material is higher than the strain-hardening, the reduced strain-hardening in the pre-deformed material should therefore have a higher tendency to form shear bands. This has been shown in pre-shocked 304L stainless steel, using hat-shaped specimens in a split-Hopkinson pressure bar equipment. It was found that the pre-shocked material offered less thermoplastic shear-instability resistance compared to the as-received, resulting in more intense shear-banding [10]. It should be noted though, that the total strain can reach levels between 1-10 in machining processes, much higher than the ones in split-Hopkinson testing [11]. This means that that there is plenty of strain hardening ability left in the pre-strained material in the present study, since only the first $30 \%$ is affected. This could also explain why there is no apparent difference in the built-up edge formation in the two material conditions. Cutting forces are also quite similar, although the pre-strained show lower values. Since the chip formation was similar for the two material conditions, the work required to produce the chips should be correlated to the area under the stress-strain curve as summed and averaged over a representative volume (length) of the chip formed. Assuming that strains are far larger than 0.3 , pre-straining should only have a small effect on the torque values, i.e. the energy spent in the cutting process.

For future testing, some other aspects may be considered, e.g. the influence of residual stresses which can reach high tensile stress levels especially during dry machining [3], as well as the surface microstructure produced by the severe local deformation conditions always present in machining, e.g. elongated grains, recrystallized grains, nano-twinning [12, 13]. Since the maximum strain levels that can be reached by tensile testing are restricted due to the necking, other methods, e.g. severe cold rolling or possibly extrusion must be used for producing the higher levels of deformation in order to enable an in-depth general understanding of the effects of the much higher local strain levels involved in any machining.

\section{Conclusions}

The following conclusions can be drawn from the present study:

- Cutting forces decreases when machining pre-deformed material.

- Main tool wear mechanism was built-up edge formation, in both the as-received and the pre-deformed material, with subsequent tool edge breakage causing large scatter in tool wear measurement.

- Pre-deformed material showed very limited burr formation as opposed to the as received material. 


\section{References}

1. Sims, C.T., N.S. Stoloff, and W.C. Hagel, Superalloys II (New York: Wiley, 1987).

2. Ezugwu, E.O., Z.M. Wang, and A.R. Machado, "The machinability of nickel-based alloys: A review," Journal of Materials Processing Technology, 1999. 86(1-3): p. 1-16.

3. Devillez, A., et al., "Dry machining of Inconel 718, workpiece surface integrity," Journal of Materials Processing Technology, 2011. 211(10): p. 1590-1598.

4. Pawade, R.S., S.S. Joshi, and P.K. Brahmankar, "Effect of machining parameters and cutting edge geometry on surface integrity of high-speed turned Inconel 718". International Journal of Machine Tools and Manufacture, 2008. 48(1): p. 15-28.

5. Zhuang, K., et al., "Notch wear prediction model in turning of Inconel 718 with ceramic tools considering the influence of work hardened layer," Wear, 2014. 313(1-2): p. 63-74.

6. Shaw, M.C., A.L. Thurman, and H.J. Ahlgren, "A Plasticity Problem Involving Plane Strain and Plane Stress Simultaneously: Groove Formation in the Machining of High Temperature Alloys," Transactions of the ASME, 1966(May): p. 142-146.

7. Komanduri, R. and T.A. Schroeder, "On Shear Instability in Machining a Nickel-Iron Base Superalloy," Journal of Engineering for Industry, 1986. 108(2): p. 93-100.

8. Komanduri, R. and Z.B. Hou, "On thermoplastic shear instability in the machining of a titanium alloy (Ti-6Al-4V)," Metallurgical and Materials Transactions A: Physical Metallurgy and Materials Science, 2002. 33(9): p. 2995-3010.

9. Cedergren, S., et al., "The effects of grain size and feed rate on notch wear and burr formation in wrought Alloy 718," The International Journal of Advanced Manufacturing Technology, 2012: p. 1-7.

10. Xue, Q., et al., "EBSD characterization of dynamic shear band regions in pre-shocked and asreceived 304 stainless steels," Materials Science and Engineering: A, 2008. 473(1-2): p. 279289.

11. Guo, Y.B., "An integral method to determine the mechanical behavior of materials in metal cutting," Journal of Materials Processing Technology, 2003. 142(1): p. 72-81.

12. Guo, Y., R. M'Saoubi, and S. Chandrasekar, "Control of deformation levels on machined surfaces," CIRP Annals - Manufacturing Technology. 60(1): p. 137-140.

13. Guo, Y., et al., "Deformation and microstructure in machining," Advanced Materials Research. 2011. p. 325-331. 